DOE/NV-358

FRMAC-10-92

REVISION 2

UC-707

JULY 1994

\title{
FEDERAL RADIOLOGICAL MONITORING AND ASSESSMENT CENTER (FRMAC) OVERVIEW OF FRMAC OPERATIONS
}

\author{
Prepared By \\ EG\&G Energy Measurements, Inc. \\ Remote Sensing Laboratory
}

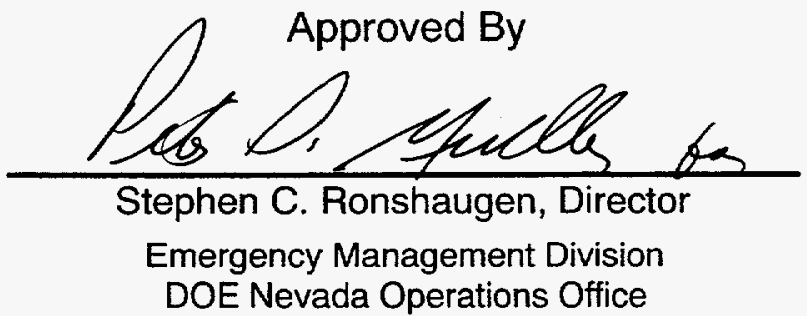

DOE Nevada Operations Office

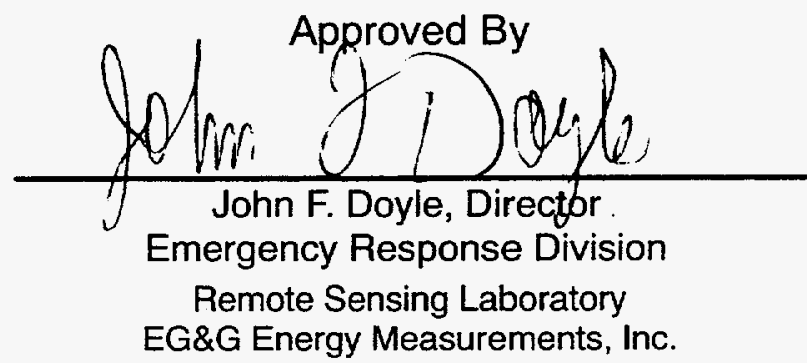

EG\&G Energy Measurements, Inc.

This Document is UNCLASSIFIED

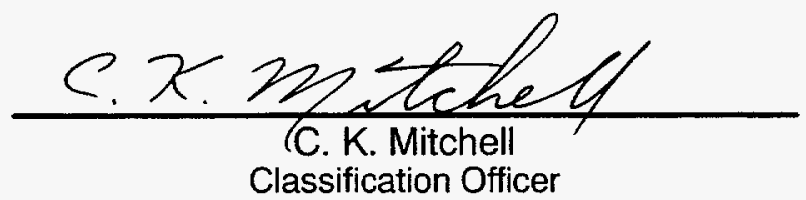

This work was performed by EG\&G/EM for the United States Department of Energy under Contract Number DE-AC08-93NV11265.

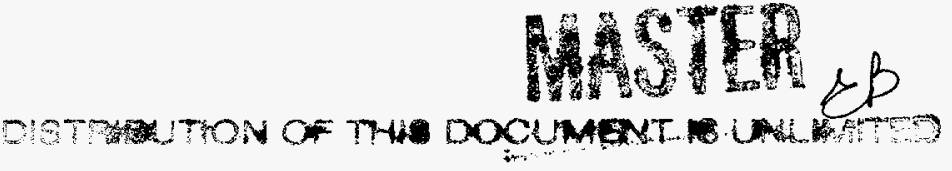




\section{DISCLAIMER}

This report was prepared as an account of work sponsored by an agency of the United States Government. Neither the United States Government nor any agency thereof, nor any of their employees, make any warranty, express or implied, or assumes any legal liability or responsibility for the accuracy, completeness, or usefulness of any information, apparatus, product, or process disclosed, or represents that its use would not infringe privately owned rights. Reference herein to any specific commercial product, process, or service by trade name, trademark, manufacturer, or otherwise does not necessarily constitute or imply its endorsement, recommendation, or favoring by the United States Government or any agency thereof. The views and opinions of authors expressed herein do not necessarily state or reflect those of the United States Government or any agency thereof. 


\section{DISCLAIMER}

Portions of this document may be illegible in electronic image products. Images are produced from the best available original document. 


\section{PREFACE}

The Federal Emergency Management Agency (FEMA) issued a Federal Radiological Emergency Response Plan (FRERP) as a Federal Register notice on November 8, 1985. The FRERP stated that Federal agencies with statutory responsibilities for emergencies involving radioactive materials have agreed to coordinate their emergency response efforts. In the event of a significant radiological emergency, a Federal Radiological Monitoring and Assessment Center (FRMAC) would be established close to the accident site to provide technical Federal assistance to the impacted State(s) and to the Lead Federal Agency (LFA) responsible for the regulation and/or operation of the accident site. The primary mission of the FRMAC is to coordinate Federal off-site radiological monitoring and assessment activities.

This document is an overview of the FRMAC Operations Plan. It will be updated (as appropriate) with the reissuance of an updated FRERP, changes in agency responsibilities, or as a result of experience gained through exercises and training. Revision 2 includes operational and organizational changes as a result of lessons learned in the FRMAC-93 and the Fremont exercises conducted in 1993. 


\section{CONTENTS}

Preface

\section{Sections}

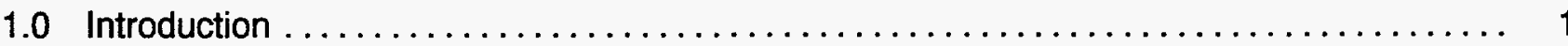

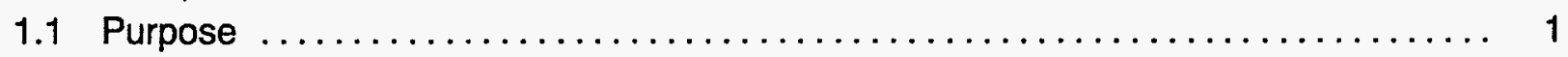

1.2 Federal Radiological Emergency Response Plan (FRERP) $\ldots \ldots \ldots \ldots \ldots \ldots \ldots \ldots$

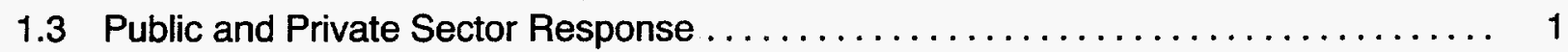

1.4 Department of Energy (DOE) Mission Under FRERP $\ldots \ldots \ldots \ldots \ldots \ldots \ldots \ldots \ldots \ldots$

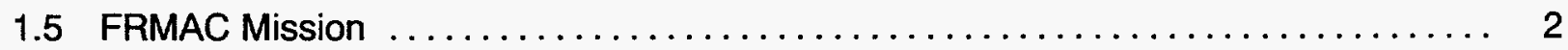

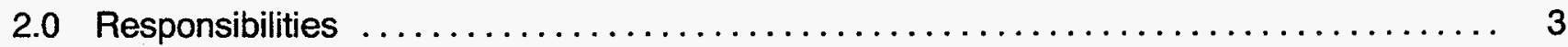

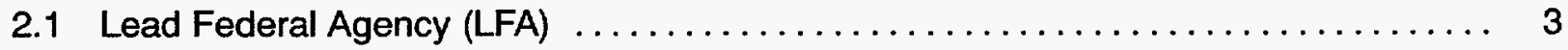

2.2 Federal Emergency Management Agency (FEMA) $\ldots \ldots \ldots \ldots \ldots \ldots \ldots \ldots \ldots$

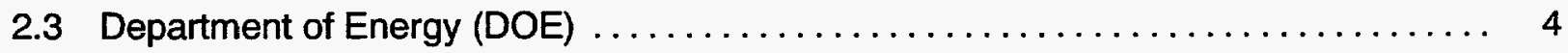

2.4 Environmental Protection Agency (EPA) $\ldots \ldots \ldots \ldots \ldots \ldots \ldots \ldots \ldots \ldots \ldots \ldots$

2.5 State and Local Governments $\ldots \ldots \ldots \ldots \ldots \ldots \ldots \ldots \ldots \ldots \ldots \ldots \ldots \ldots \ldots$

2.6 Advisory Team for Environment, Food, and Health (Advisory Team) $\ldots \ldots \ldots \ldots \ldots$

2.7 Other Federal Agencies $\ldots \ldots \ldots \ldots \ldots \ldots \ldots \ldots \ldots \ldots \ldots \ldots \ldots \ldots \ldots \ldots$

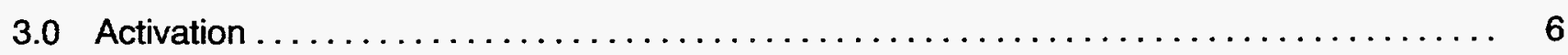

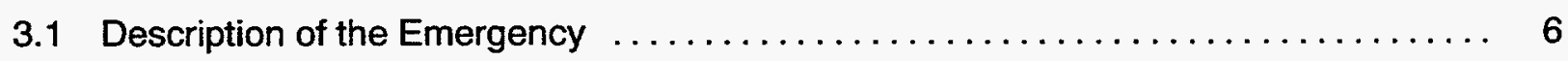

3.2 Call-Up Procedures/Authorities $\ldots \ldots \ldots \ldots \ldots \ldots \ldots \ldots \ldots \ldots \ldots \ldots \ldots \ldots$

3.3 Radiological Assistance Program (RAP) Response $\ldots \ldots \ldots \ldots \ldots \ldots \ldots \ldots \ldots$

3.4 FRMAC Activation Stages and Timelines $\ldots \ldots \ldots \ldots \ldots \ldots \ldots \ldots \ldots \ldots \ldots \ldots$

3.5 Resources Available for Deployment $\ldots \ldots \ldots \ldots \ldots \ldots \ldots \ldots \ldots \ldots \ldots \ldots$

3.5.1 Atmospheric Release Advisory Capability $\ldots \ldots \ldots \ldots \ldots \ldots \ldots \ldots \ldots \ldots$

3.5.2 Radiation Emergency Assistance Center/Training Site $\ldots \ldots \ldots \ldots \ldots \ldots \ldots .9$

3.5.3 Aerial Measuring System $\ldots \ldots \ldots \ldots \ldots \ldots \ldots \ldots \ldots \ldots \ldots \ldots \ldots \ldots$

3.5.4 FRMAC Advance Party $\ldots \ldots \ldots \ldots \ldots \ldots \ldots \ldots \ldots \ldots \ldots \ldots \ldots \ldots$

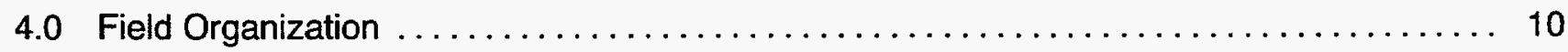

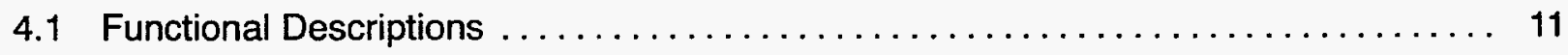

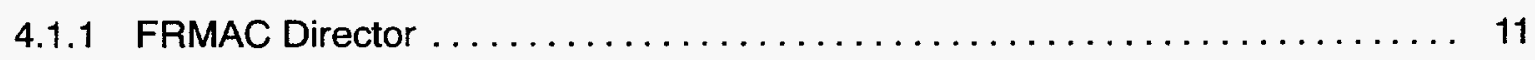

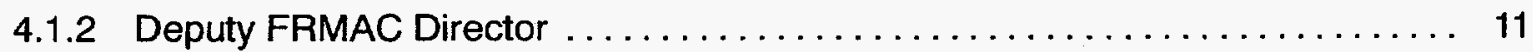


4.1.3 State and LFA Representatives to the FRMAC Director $\ldots \ldots \ldots \ldots \ldots \ldots \ldots$

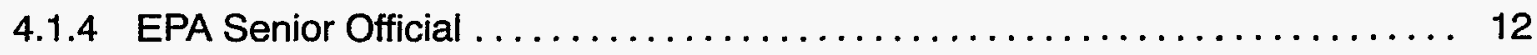

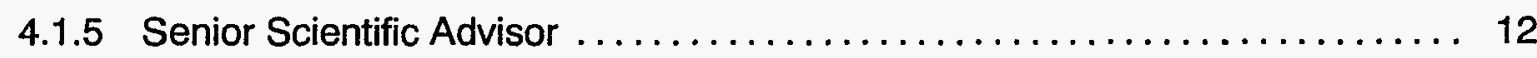

4.1.6 Representatives from Other Agencies to the FRMAC $\ldots \ldots \ldots \ldots \ldots \ldots \ldots . \ldots \ldots$

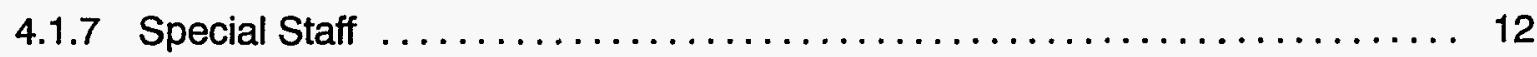

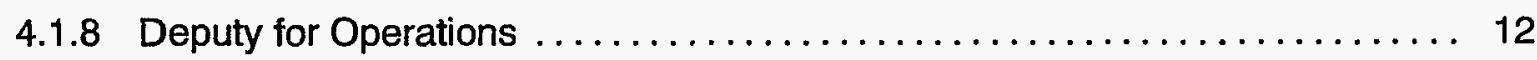

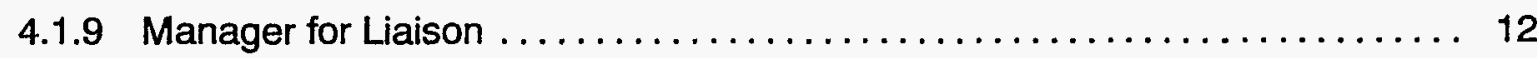

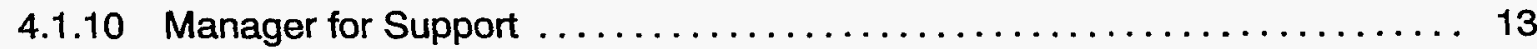

4.1.11 Manager for Monitoring and Analysis (M\&A) .................. 13

4.1.12 Manager for Evaluation and Assessment (E\&A) $\ldots \ldots \ldots \ldots \ldots \ldots \ldots \ldots$

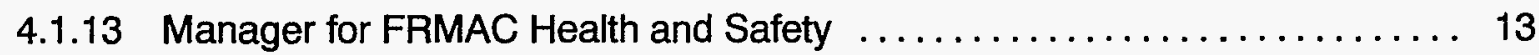

4.2 FRMAC Site Selection Considerations $\ldots \ldots \ldots \ldots \ldots \ldots \ldots \ldots \ldots \ldots \ldots \ldots \ldots$

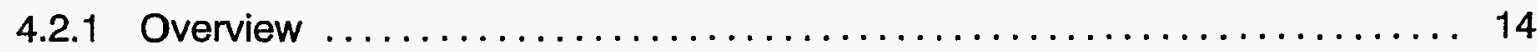

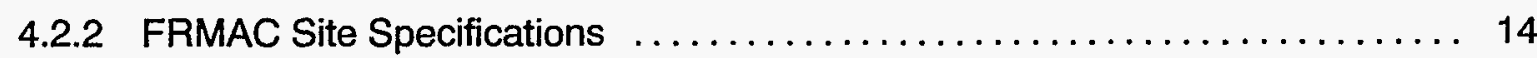

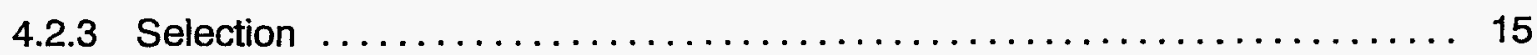

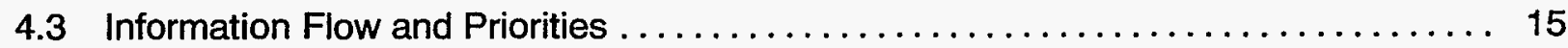

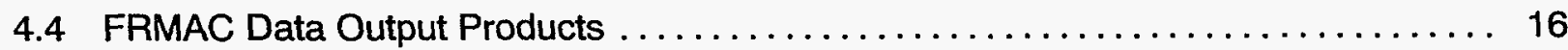

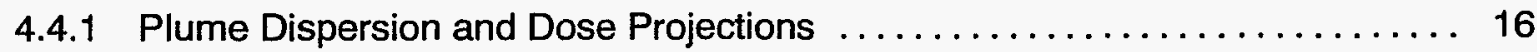

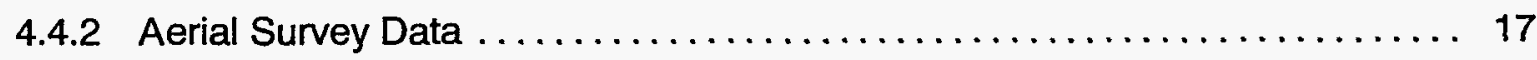

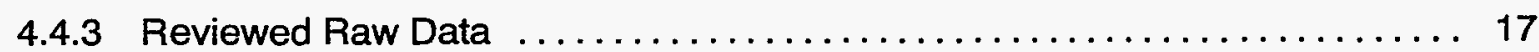

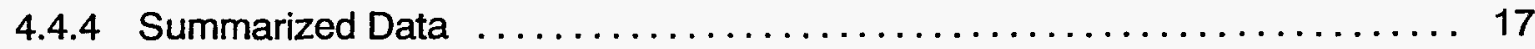

4.4.5 Exposure Rate and/or Contamination Contours .................. 18

4.4.6 Dose Projections from Actual Measurements $\ldots \ldots \ldots \ldots \ldots \ldots \ldots \ldots \ldots . \ldots \ldots$

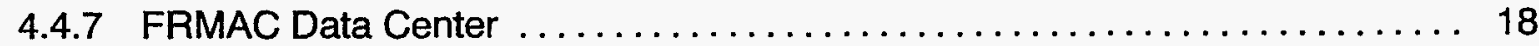

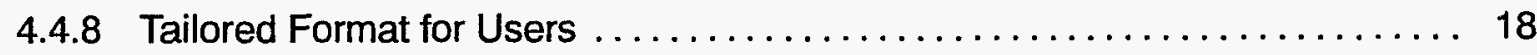

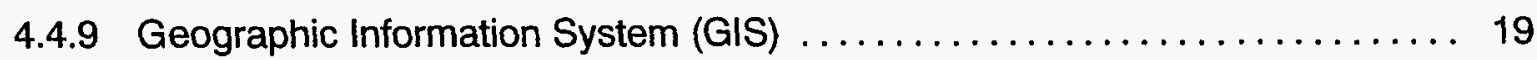

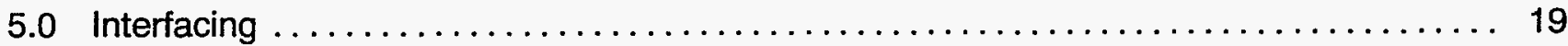

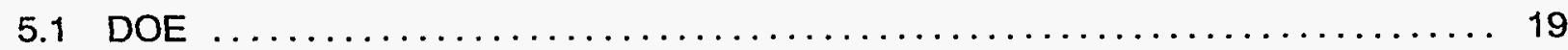

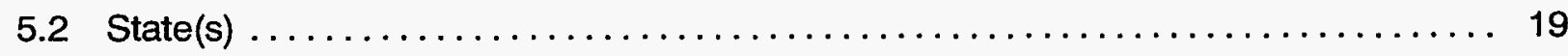

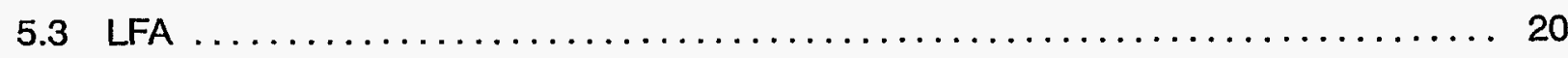

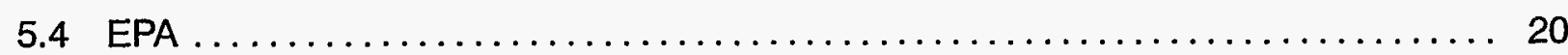

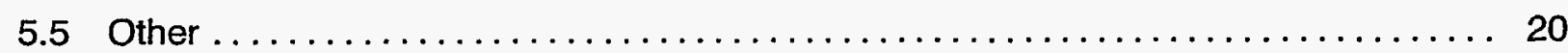

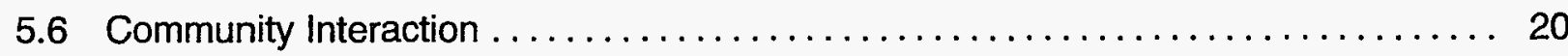

\section{Figures}

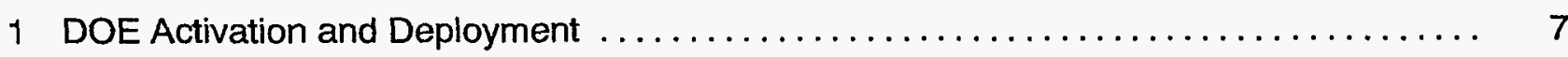


2 Approximate Arrival Times for Various DOE Assets $\ldots \ldots \ldots \ldots \ldots \ldots \ldots \ldots \ldots \ldots \ldots .8$

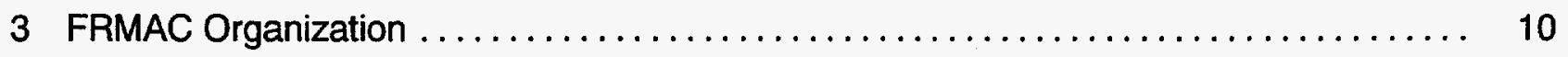

4 FRMAC Environmental Data Information Flow $\ldots \ldots \ldots \ldots \ldots \ldots \ldots \ldots \ldots \ldots \ldots \ldots$

\section{Table}

1 Identification of Lead Federal Agencies for Radiological Emergencies

\section{Appendix}

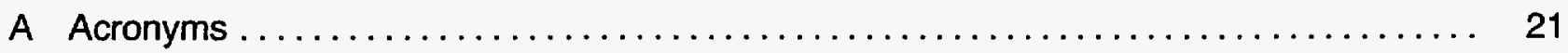

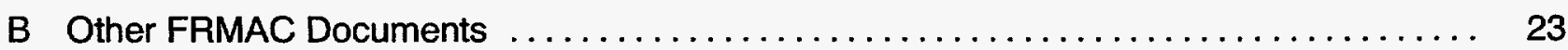

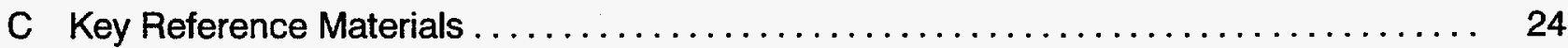




\subsection{INTRODUCTION}

\subsection{Purpose}

The purpose of this overview of the Federal Radiological Monitoring and Assessment Center (FRMAC) operations is to describe the FRMAC response to a major radiological emergency and to describe the subsequent response activities which provide radiological monitoring and assessment outside the immediate boundaries of the radiological emergency site.

In the event of a major radiological emergency, Federal agencies with various statutory responsibilities have agreed to coordinate their efforts at the emergency scene under the umbrella of the Federal Radiological Emergency Response Plan (FRERP). This cooperative effort will assure the State(s) and a designated Lead Federal Agency (LFA) that all Federal radiological assistance is fully supporting their efforts to protect the public and will provide monitoring and assessment results for their immediate use in decision making. The Federal agencies do not relinquish their statutory responsibilities. However, the mandated Federal cooperation ensures that each agency can obtain the data critical to its specific responsibilities.

\subsection{Federal Radiological Emergency Response Plan (FRERP)}

The FRERP, which is designed to ensure a coordinated Federal response to a radiological emergency, describes how this response will be organized. The FRERP covers any radiological emergency, not related to National Security, that has or is expected to have a radiological effect within the United States, its territories, reservations, possessions, or territorial waters and which could require a response by several Federal agencies.

The Plan suggests ways in which the Federal, State, and local agencies can most effectively integrate their actions. The degree to which the Federal response is merged or activities are adjusted will be based upon the requirements and priorities set by the State.

In the Plan, "on-site" refers to the area inside the fence line or property line of the facility which is experiencing the emergency, or if a nuclear weapon is involved, inside a Federal government-defined National Defense Area or National Security Area. "Off-site" applies to all other areas.

\subsection{Public and Private Sector Response}

State, Tribal, county, and/or city governments have primary responsibility for determining and implementing any measures to protect life, property, and the environment in any areas outside the boundaries of a fixed nuclear facility or not under the control of a Federal agency. The owner or operator of a nuclear facility has primary responsibility for actions within the boundaries of that facility, for providing notification and advice to off-site officials, and for minimizing the radiological hazard to the public. 
For emergencies involving an area under Federal control, the responsibility for on-site actions belongs to a Federal agency, while off-site actions are the responsibility of the State, Tribal, and/or local governments. For all other emergencies, the State, Tribal, and/or local government has the responsibility for taking emergency actions, both on-site and off-site.

Because the assignment of specific responsibilities for protection of the public varies from State to State, and Tribal, county, and city interests are involved as well, this overview will employ the term local authorities to address, generically, the local group in the public sector that has radiological protection responsibilities for the public.

\subsection{Department of Energy (DOE) Mission Under FRERP}

The FRERP assigns to the DOE the responsibility for establishing a FRMAC to provide an operational framework for coordinating the Federal off-site radiological monitoring and assessment activities during a response to a radiological emergency. In 1987, DOE Headquarters assigned the responsibility for establishing and managing a FRMAC to the DOE Nevada Operations Office (DOE/NV).

\subsection{FRMAC Mission}

A FRMAC is established in response to a State or LFA request when a major radiological problem is anticipated or has occurred. The FRMAC becomes a coalition of all Federal off-site monitoring and assessment efforts to assist the State(s) and local authorities. The State and local agencies are invited to participate in the FRMAC, as appropriate. The participants in FRMAC operations, then, become members of the FRMAC and their allegiance is with the FRMAC, rather than to their respective agencies. Agency representatives are in the FRMAC, as appropriate, as a separate group not involved in the operational activities.

The FRMAC will coordinate all off-site Federal monitoring efforts to provide the following support and radiological information to the State(s) and the LFA in a timely manner:
A. Plume and deposition predictions, as appropriate
B. Air and ground concentrations
C. Deposition patterns of isotopic concentrations, exposure rates, and dose projections
D. Isotopic concentrations in environmental media
E. Assurance of data quality
F. Archival database containing complete retrievable electronic media and hard copy of all off-site environmental radiological measurements and related information
G. Results of data collection, analysis, and evaluation
H. Evaluations, assessments, and interpretation of data, as applicable 
I. Technical assistance to State(s), LFA, and local authorities to the extent resources are available

J. Current meteorological conditions and weather forecasts

\subsection{RESPONSIBILITIES}

The responsibilities for management of a response to a radiological emergency are divided among several agencies. These responsibilities are discussed below.

\subsection{Lead Federal Agency (LFA)}

The LFA is the agency which has cognizance of all aspects of the Federal response. The LFA is normally the Federal agency that owns, authorizes, regulates, or is otherwise deemed responsible for the facility or radiological activity causing the emergency, and has authority to take action on-site. The designation of LFAs is summarized in Table 1.

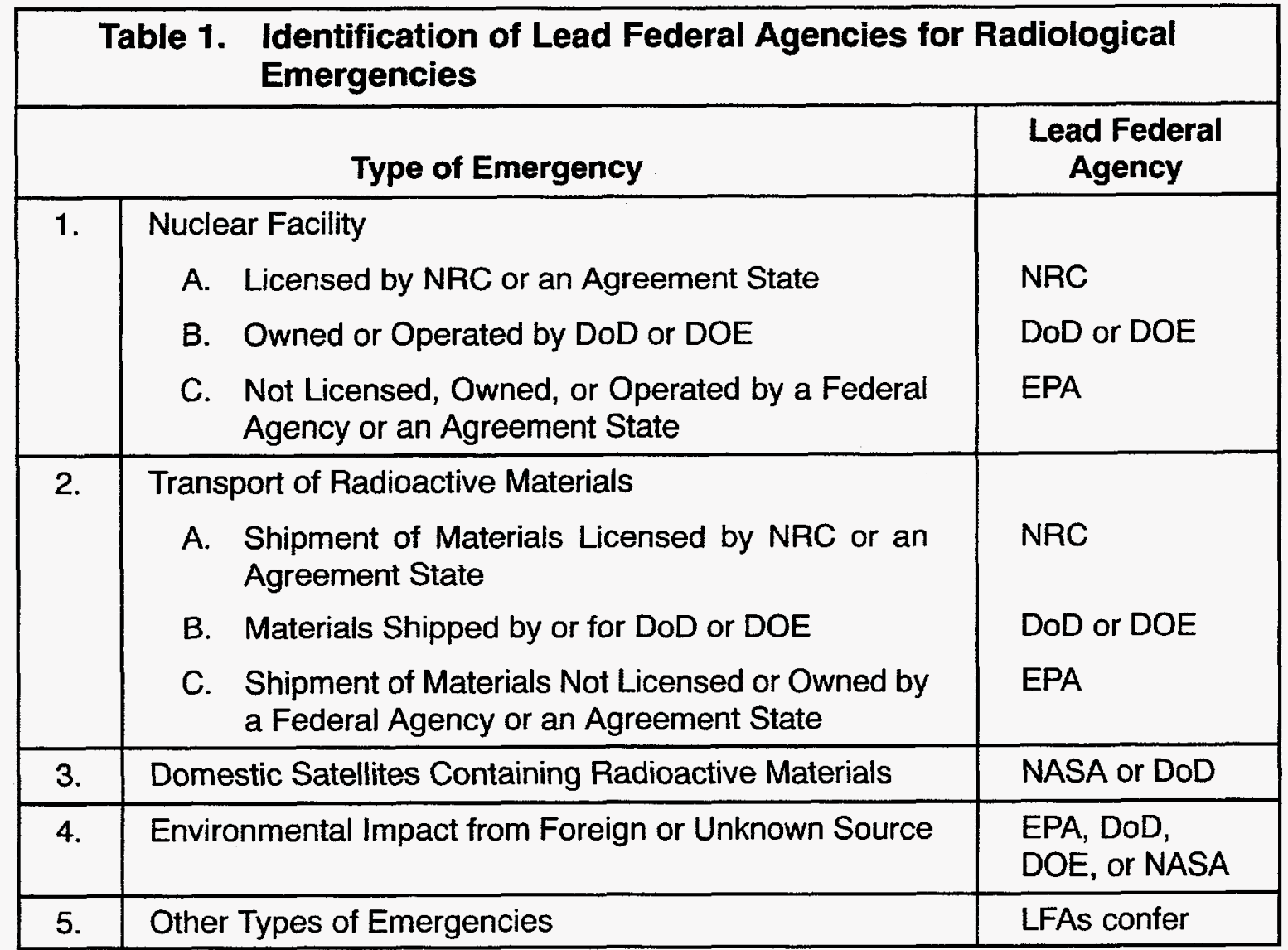


The LFA will:

A. Coordinate the overall Federal response.

B. Oversee on-site response and support operator activities.

C. Assist State(s) and local authorities in determining measures to protect life, property, and the environment.

D. Provide and coordinate protective action recommendations to the State(s) and local authorities.

E. Ensure Federal agencies assist State(s) and local authorities in implementing protective actions, if requested.

F. Serve as the principal Federal source of information on on-site conditions; coordinate all public information on Federal response activities, information for Congress, the White House, and the Department of State.

G. Establish on-scene response centers (the Joint Operations Center is the coordination center for the overall Federal response; the Joint Information Center coordinates information to the public/media).

H. Coordinate the overall activity of Federal agencies involved in the recovery process.

\subsection{Federal Emergency Management Agency (FEMA)}

As defined by the FRERP, the Senior FEMA Official (SFO) will coordinate the overall Federal off-site support to the State(s) and local authorities. The general responsibilities of the SFO and the FEMA Emergency Response Team are to:

A. Promote coordination among Federal agencies and their interactions on non-technical issues with the State(s) and local authorities.

B. Serve as the coordinator for information related to the Federal non-radiological response.

C. Provide support to the JIC.

\subsection{Department of Energy (DOE)}

Under the FRERP, the DOE establishes and manages the FRMAC during the initial phase of the emergency. Those responsibilities are to:

A. Provide technical support to the State(s), LFA, and local authorities by establishing the FRMAC and coordinating the off-site Federal radiological monitoring, assessment, and evaluation.

B. Maintain liaison with the State(s), LFA, and local authorities.

C. Maintain a common and complete set of off-site radiological monitoring and sampling data.

D. Provide data and interpretation of those data to the LFA and appropriate Federal, State, and local agencies, as requested. 
E. Provide the LFA with radiological information to be used in its development or evaluation of protective action and recovery recommendations for the public, as required.

F. Provide various operational assets, including radiation detection and measurement equipment, communications support, and aerial monitoring capability, as appropriate.

G. Following the initial phase of the emergency, provide off-site support to EPA when they assume management of the FRMAC.

\subsection{Environmental Protection Agency (EPA)}

The EPA provides a Senior Official to the FRMAC as soon as it is deployed to assist the operation of the FRMAC from the EPA perspective. This official (or others from EPA) may participate in advisory teams or other groups set up to support the LFA.

Following the emergency phase, at a mutually agreeable time, the DOE, in coordination with the LFA, EPA, the State(s), and FEMA, will transfer FRMAC management responsibilities to the EPA's Office of Radiation and Indoor Air (ORIA). The EPA/ORIA will assume the Federal agency responsibility for coordinating the intermediate and long-term off-site radiological monitoring, sampling, and assessment activities. When the EPA/ORIA accepts control of the FRMAC, DOE and other Federal agencies will continue to commit the equipment, personnel, and funds for the duration of the Federal response effort as necessary.

\subsection{State and Local Governments}

State and local authorities are responsible for the health and welfare of the general public during an emergency. They will assess the situation and issue instructions for necessary protective actions. The State receives protective action recommendations (PARs) from the LFA as the primary Federal channel for such recommendations.

\subsection{Advisory Team for Environment, Food, and Health (Advisory Team)}

The LFA will be assisted by an Advisory Team composed of the EPA, Health and Human Services (HHS), and United States Department of Agriculture (USDA). This team will use FRMAC data and assessments to assist the LFA in the development of Federal protective action recommendations. The Advisory Team will work with the LFA to request FRMAC monitoring and assessment results.

The Advisory Team will likely collocate with the FRMAC to have easy access to the FRMAC data assessments and to accommodate the needs of the State(s).

\subsection{Other Federal Agencies}

All other Federal agencies not previously identified as having a management and/or support role will respond in accordance with the FRERP at the request of FEMA, the LFA, DOE, the impacted State(s), 
or in accordance with established statutory responsibilities. The HHS, USDA, and EPA will assist the State(s) and LFA in interpreting their published guidelines on protective actions.

\subsection{ACTIVATION}

\subsection{Description of the Emergency}

When DOE is formally notified of a radiological emergency, the DOE response element managers will obtain as detailed a description as possible of the emergency. In order to assure a timely and appropriate response, effort will be made to determine:

A. The type of facility or radiological material involved in the emergency (e.g., a power reactor, a nuclear weapon, transportation).

B. The location of the emergency and the nearest major city or town.

C. An estimate of the source term and isotope(s) involved and the chemical and physical form, if known.

D. The name and telephone number of a technical person from the reporting organization who is knowledgeable of the radiological situation.

E. The extent of knowledge about the release and distribution, i.e., whether release is dynamic or has ceased.

F. The meteorological conditions at the time of the emergency.

\subsection{Call-Up Procedures/Authorities}

Part II of the FRERP (Concept of Operations) requires the LFA to notify the State(s), FEMA, DOE, $E P A$, and other Federal agencies of the emergency and its apparent severity. DOE procedures will activate the FRMAC and the Federal agencies and contractors which support the FRMAC.

As an example, in the event of an emergency at a licensed nuclear facility, the NRC and DOE have developed an Alert and Activation Procedure. This procedure assures an almost continuous dialogue between NRC Headquarters Operations Center and the DOE Headquarters Operational Emergency Management Team (OEMT), from the onset of an emergency through deployment of response resources. Figure 1 is a flow chart of the DOE activation and deployment activities.

\subsection{Radiological Assistance Program (RAP) Response}

Each of the eight DOE Regional Coordinating offices, which manage major DOE nuclear facilities and laboratories throughout the United States, maintains 24-hour response capabilities for radiological emergencies which may occur in states served by each region. Telephone numbers for the DOE Regional Operations Office are provided to the various State agencies in their region. Due to their 


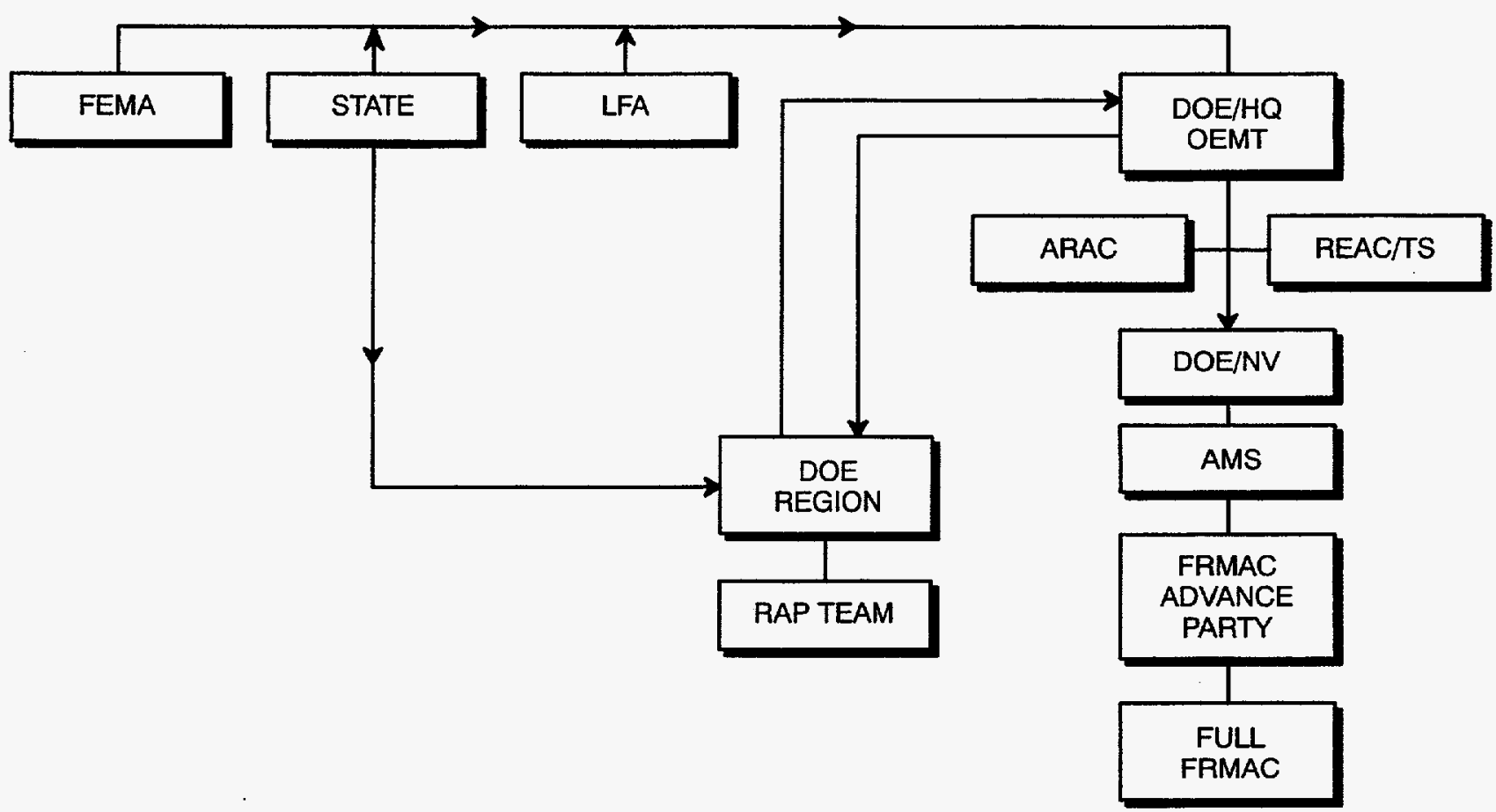

FIGURE 1. DOE ACTIVATION AND DEPLOYMENT

close proximity, the RAP Teams can be expected on the scene within two to six hours after notification to assist the State(s) and LFA. These teams are equipped with monitoring equipment and protective clothing and can provide a significant early assessment of the radiological situation. The Concept of Operations for the RAP response in this context is provided in DOE Order 5530.3.

The DOE Operations Regional Response Coordinator informs the DOE HQ OEMT of a RAP response and the status of that response. If the early assessment indicates the emergency may exceed the RAP Teams' resource capabilities, the DOE HQ OEMT will, after coordinating with DOE HQ/Germantown, activate the FRMAC response through the DOE/NV Emergency Operations Center (DOE/NV EOC) and ensure coordination of those activities with the LFA and affected State(s).

\subsection{FRMAC Activation Stages and Timelines}

When notified that a FRMAC response is required, the Manager of DOE/NV designates the FRMAC Director and initiates FRMAC deployment. An advance party will then depart for the emergency site within two to six hours. General FRMAC deployment will follow. The full FRMAC will be established within 24 to 36 hours. The FRMAC may deploy as few as 20 , or as many as 300 or more people to the site of the emergency to assist the State(s), LFA, and local authorities in off-site monitoring and assessment. The FRMAC will function as a self-sufficient facility, designed to augment rather than burden local resources. Figure 2 identifies the response assets and approximate arrival times. 


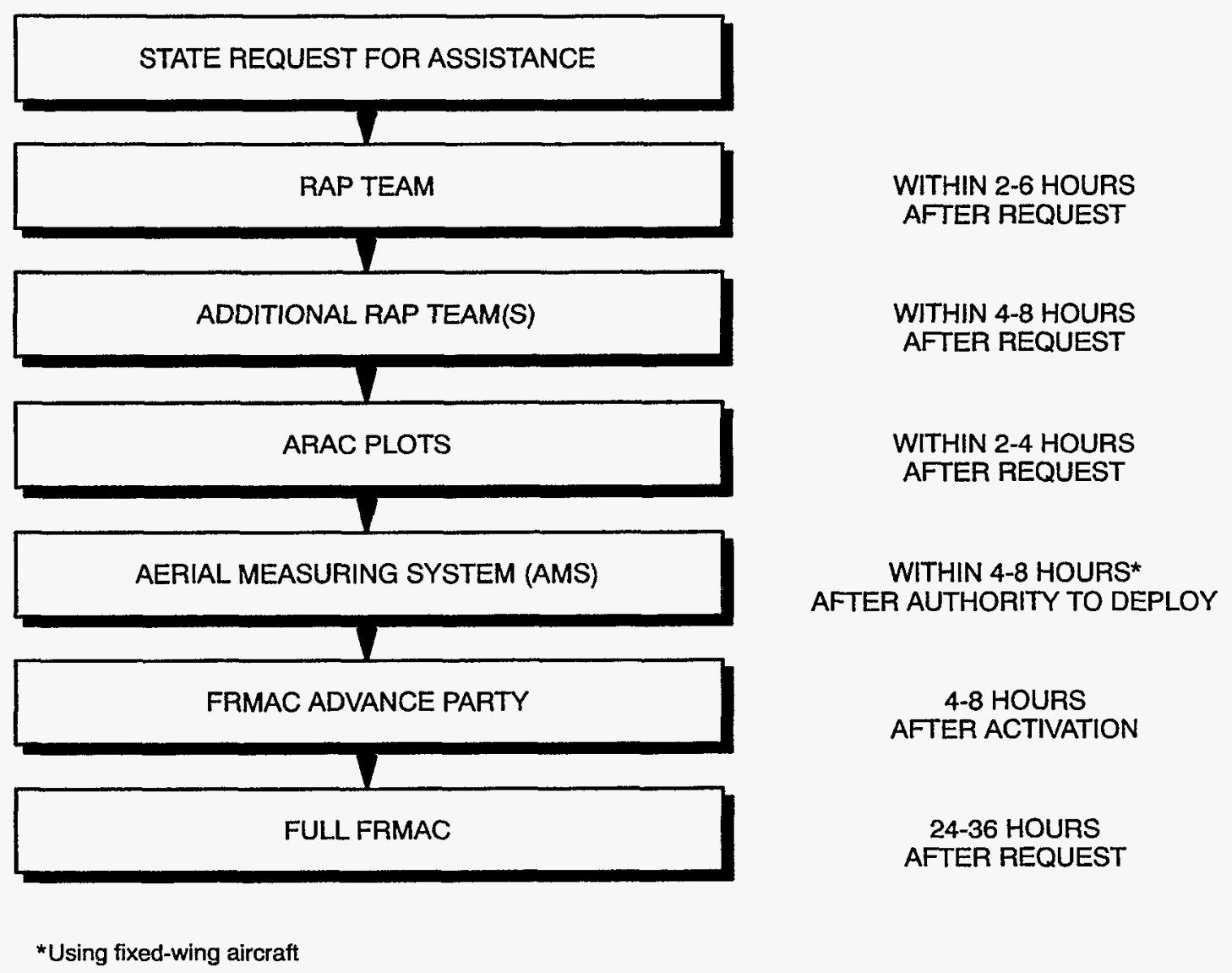

FIGURE 2. APPROXIMATE ARRIVAL TIMES FOR VARIOUS DOE ASSETS

\subsection{Resources Available for Deployment}

The DOE and the EPA provide significant radiation monitoring, analysis, and assessment equipment with highly skilled professionals. In addition, the DOE FRMAC team provides the essential communication, photo/video, computer network, and mechanical/electrical support to establish a FRMAC operations and work area for the Federal monitoring and assessment effort. The total amount of equipment needed may require several C-141 aircraft. Both fixed (permanent facility) and mobile laboratories are available from DOE, EPA, and other Federal agencies. The following assets will be selected and deployed, depending upon the real or potential impact of the emergency.

\subsubsection{Atmospheric Release Advisory Capability}

The Atmospheric Release Advisory Capability (ARAC) at Lawrence Livermore National Laboratory in California may provide valuable guidance prior to FRMAC activation. ARAC can be activated at the request of the RAP team, the DOE Regional Coordinating Office, the DOE/NV office, or DOE Headquarters EOC. The DOE Headquarters EOC coordinates requests for and approval of the use of ARAC for emergencies. 
ARAC personnel, located within the Evaluation and Assessment Division, produce contour plots of air concentration, airborne dose, ground deposition, or ground exposure dose overlaid on a map of the accident area. ARAC aids in assessing downwind areas receiving significant radiation dose and deposition, and also in the deployment of field teams, AMS survey plans, and source strength estimates.

\subsubsection{Radiation Emergency Assistance Center/Training Site}

The Radiation Emergency Assistance Center/Training Site (REACTS), located in Oak Ridge, Tennessee, provides direct support, including deployable medical and health physics personnel who are first-line responders. These highly trained personnel specialize in handling victims of radiation emergencies and other types of physical injuries.

REAC/TS and other emergency medical coordinators work within the FRMAC Health and Safety Division furnishing information to the FRMAC Director in the event that radiological medical support is requested by a Federal agency or the State(s). REAC/TS personnel are on 24-hour call to provide first-line responders with consultative or direct medical and radiological assistance.

\subsubsection{Aerial Measuring System}

The Aerial Measuring System (AMS) helicopters and fixed-wing aircraft, operated for DOE by EG\&G Energy Measurements, Inc. (EG\&G/EM), are equipped to measure radioactive material deposited on the ground and to perform plume tracking. The aircraft, permanently based at Andrews AFB near Washington, D.C., and at Nellis AFB near Las Vegas, Nevada, are a key element of a response to an accident involving dispersal of radioactivity over a large area. The aerial response can occur in the same time frame as the advance party deployment.

The AMS program has maintained and updated background radiological surveys of major nuclear facilities in the United States for the past 30 years. These survey results will be used as a baseline for determining even extremely low-level releases of radioactivity from an accident or incident at one of the sites.

\subsubsection{FRMAC Advance Party}

The FRMAC Advance Party, consisting of approximately 10 key personnel, is selected by the FRMAC Director. After receiving notification to deploy, the Advance Party will arrive at the emergency location within about four to eight hours. They will establish communications with the State(s) and the LFA, determine their requirements, define the appropriate level and composition of a FRMAC response, and locate a suitable site for an operational FRMAC.

The Advance Party will meet with the the State(s) and the LFA to obtain the status of the emergency, public protective actions which have been initiated, available monitoring data, and any other pertinent 
information. During this meeting, FRMAC, State and LFA liaisons will be identified and the initial FRMAC Monitoring and Sampling Plan will be agreed upon. This plan will reflect the State and LFA requirements and emphasize public safety by monitoring where people are located, providing monitoring data to estimate the validity of the dispersion and deposition models in use, and characterizing the off-site area.

\subsection{FIELD ORGANIZATION}

Figure 3 is a FRMAC Organization chart for which plans and procedures have been developed and refined. The organizational structure has been adapted from those used in many exercises, including full-field nuclear power plant and other field activities. The complete chart of key personnel represents the requirements needed to implement FRMAC operations in the event of a large, full-scale deployment due to a major radiological emergency. In the event of a less significant incident, the FRMAC concept would remain the same; however, some job functions might be combined.

The parenthetical notes on the organizational chart indicate locations from which personnel may be drawn to fill these management positions. The notation "NV" means that DOE/NV and/or DOE/NV contractors will most likely fill the designated positions. The notation "Region" means that those positions will most likely be filled by the DOE Operations Office and/or contractors where the emergency

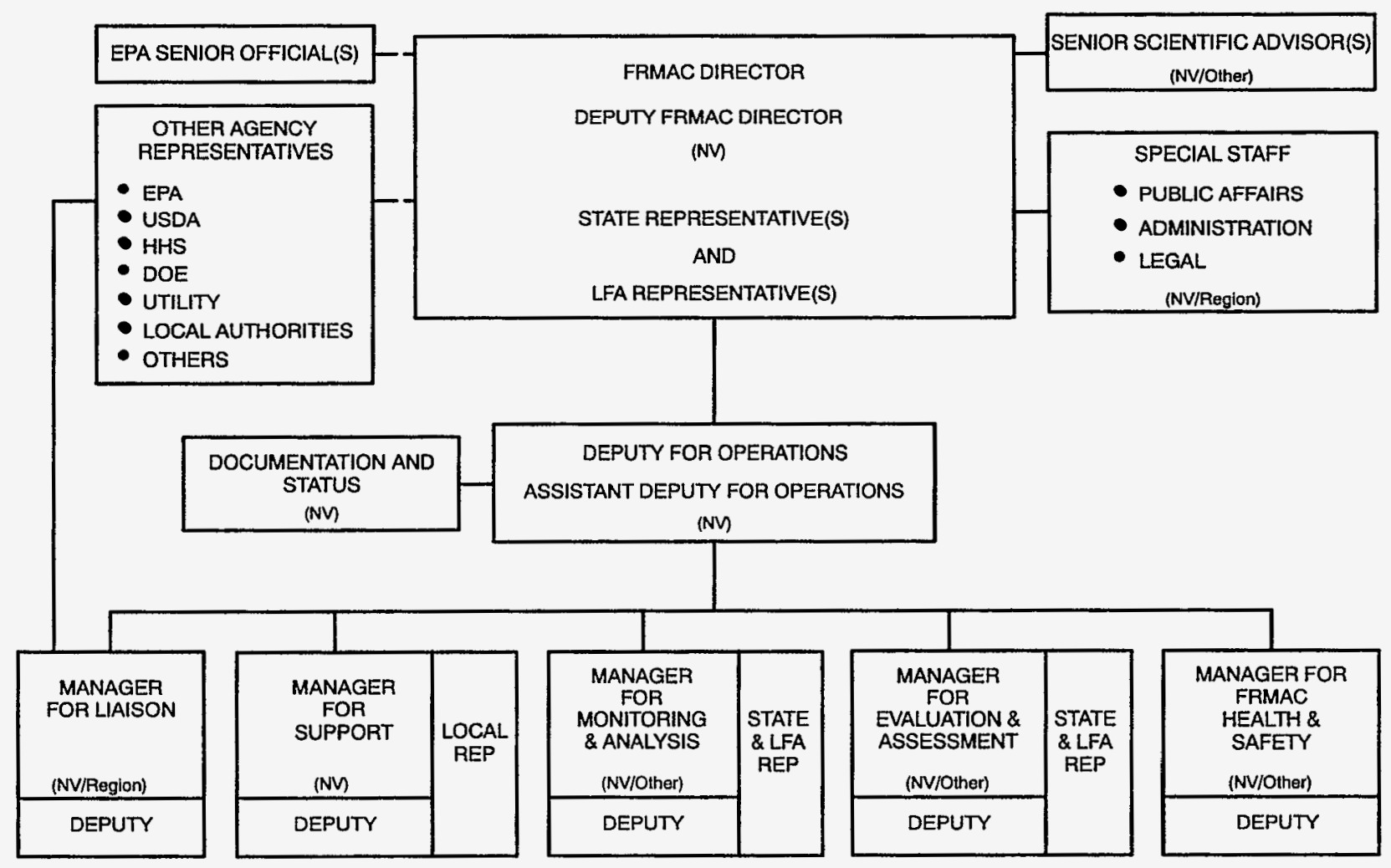

FIGURE 3. FRMAC ORGANIZATION 
occurs. The notation "NV/Other" means that the position(s) may be filled by DOE/NV, DOE Regional, or other agencies.

Since the FRMAC is established to assist the State(s), LFA, and local authorities, their representatives interface closely with the FRMAC Director and his staff. These representatives are the source of their organization's requests for FRMAC products and senvices. They are responsible for delivering their organization's requests to the Director and staff. Technical representatives from these organizations are located at key positions in the FRMAC to help implement their organization's needs.

The chart shows heavy participation by the State and LFA. Since the State and LFA are basically the customers of the FRMAC, they play a major role in setting overall FRMAC priorities and in interfacing with FRMAC activities.

\subsection{Functional Descriptions}

Key FRMAC personnel are described in functional profiles.

\subsubsection{FRMAC Director}

The FRMAC Director, appointed by DOE/NV, is the senior DOE official managing the FRMAC during the emergency phase of the accident or incident. This person directs the activities of all FRMAC personnel provided by any DOE Operations Office, DOE laboratory, DOE contractor, or other Federal or State agencies. The Director is responsible for the overall execution and success of the FRMAC response. The Director is also responsible for establishing communication with the State(s), the LFA, local authorities, and other Federal agencies to carry out the objectives and operations of the FRMAC.

\subsubsection{Deputy FRMAC Director}

The Deputy FRMAC Director will be responsible for information flow within the FRMAC and for assuring the completion of each request made by the State(s) and LFA. The Deputy Director will serve as a conduit for information provided to the FRMAC Director by the operating Deputies and Managers (the Support Manager, the Evaluation and Assessment Manager, the Monitoring and Analysis Manager, and the FRMAC Health and Safety Manager), and review all data prior to presenting it to the Director.

\subsubsection{State and LFA Representatives to the FRMAC Director}

The State and LFA representatives work directly with the FRMAC Director and Deputy in establishing FRMAC priorities and in reviewing the overall FRMAC activities. The LFA representative coordinates requests from the participating Federal agencies and, with the State(s) representative, provides input to the FRMAC Director about overall needs for off-site monitoring and assessment to fulfill the priorities of the State(s) and LFA. 


\subsubsection{EPA Senior Official}

The EPA plays a major role in the FRMAC operations because the agency becomes responsible for FRMAC management after the emergency phase is over. The senior EPA official, who is from the EPA's Office of Radiation and Indoor Air (ORIA), functions as a senior staff liaison official and interfaces directly with the FRMAC Director. In addition, the senior EPA official will advise the FRMAC Director on EPA protective action guides (PAGs).

\subsubsection{Senior Scientific Advisor}

The Senior Scientific Advisor (SSA) will be a national expert in radiation health effects and environmental impacts of the radioactive material involved. The SSA (with staff, if needed) will provide an overview to the FRMAC Director about the health effects and environmental impacts of the emergency. The SSA will advise the FRMAC Director about operational activities to meet the overall FRMAC objectives and will work closely with the technical managers in the field organization.

\subsubsection{Representatives from Other Agencies to the FRMAC}

Federal agencies that need technical information to fulfill their statutory obligations are represented at the FRMAC but are not part of the FRMAC operations. The DOE representative provides FRMAC operations information to DOE/HQ, DOE/NV, and DOE/Region. Other local agencies within the State(s) may also be represented. The allegiance of these representatives remains with their own agencies, not the FRMAC.

\subsubsection{Special Staff}

The Special Staff assists and advises the FRMAC Director concerning administrative, legal, and public affairs. The Legal Coordinator will provide legal advice to the FRMAC Director concerning FRMAC operations and personnel. The Public Affairs Officer (PAO) will advise the FRMAC Director about news media activities associated with the emergency and will interface with the State and LFA PAOs and media personnel, where appropriate.

\subsubsection{Deputy for Operations}

The Deputy for Operations assists and advises the Director in field implementation, execution, and coordination of all resources at the FRMAC. The Deputy for Operations advises the Director about all staff and emergency functions and monitors the status of all requests and events flowing through the FRMAC.

\subsubsection{Manager for Liaison}

The Manager for Liaison will coordinate information through FRMAC technical liaison representatives to the State(s), LFA, and local authorities, FEMA's Disaster Field Office (DFO), and other agencies and/or emergency response centers, as needed. 
The liaison function ensures timely transmittal of critical monitoring and assessment information to the State(s), the LFA, the facility operator (if there is one), and other Federal agencies, as approved by the State(s) and the LFA. The resolution of conflicts in data from other sources is facilitated and expedited through the FRMAC liaison personnel who are assigned to the response facilities. Liaisons are located in other response centers (not the FRMAC). They communicate with the FRMAC by telephone, fax, modem, and still video.

\subsubsection{Manager for Support}

The Manager for Support is responsible for providing administrative services, communications, mechanical systems support, photographic and video support, logistics support, security, and general supplies and services (base support) to all FRMAC participants.

\subsubsection{Manager for Monitoring and Analysis (M\&A)}

The Manager for Monitoring and Analysis will coordinate and direct data acquisition personnel, including those responsible for aerial radiological surveying, field monitoring, sampling, sample analysis, and environmental dosimetry. All environmental monitoring teams working out of the FRMAC (including DOE, the EPA, other Federal agencies, and the State[s]) will be coordinated by the Manager. In conjunction with the Senior Scientific Advisor and the Manager for Evaluation and Assessment, the Manager for M\&A evaluates the need for field information and radioanalytical data, and establishes priorities for the M\&A resources. The Quality Assurance Group within the M\&A assures that all monitoring measurements, sample collection, and derived analytical data are scientifically defensible, of acceptable known quality, and meet FRMAC requirements.

\subsubsection{Manager for Evaluation and Assessment (E\&A)}

All environmental radiation data that are gathered or received by the FRMAC flow through the E\&A Division to the FRMAC Director. The Manager oversees the handling, processing, evaluation, assessment, reporting, and archiving of all the data; reviews and assembles all of the environmental data to develop an overview status and to provide technical interpretation of the radiological situation; and ensures that the appropriate documents exist to assure the technical integrity of the data.

The Manager for E\&A works closely with the Senior Scientific Advisor to identify monitoring and radioanalytical data needed to meet FRMAC assessment requirements. Both work closely with the Manager for M\&A in establishing priorities for the monitoring and laboratory resources which most efficiently meet these data requirements.

\subsubsection{Manager for FRMAC Health and Safety}

The Manager for FRMAC Health and Safety is responsible for all health and safety issues for FRMAC personnel. This includes health physics, industrial hygiene, general safety, and medical care or 
treatment at the FRMAC and for all Federal and Federal contractor FRMAC participants. The manager will coordinate and direct all health and safety efforts in conjunction with the other FRMAC managers and will ensure that personnel radiation exposures are maintained at levels as low as reasonably achievable (ALARA) within the appropriate exposure standards. The Safety Coordinator (within this group) will work with the FRMAC managers to ensure that all FRMAC operations (both inside the FRMAC building and outside in field operations) are being conducted in a safe manner and in compliance with all DOE orders or other applicable Federal regulations. Within the Health and Safety Division are personnel from the Radiation Emergency Assistance Center/Training Site (REAC/TS) and/or the regional medical coordinator who will provide information to the FRMAC Director in the event that radiological medical support is requested by a Federal agency or the State(s).

\subsection{FRMAC Site Selection Considerations}

\subsubsection{Overview}

FRMAC is designed to be self-supporting and comes to assist the State(s), not to be a burden. The selection of a FRMAC site must include consideration of housing, airport facilities, and vehicle availability. All of these may be affected by the magnitude of the emergency, evacuation status, presence of an airborne radioactive plume, and other factors that will only be known at the time of the emergency. In addition, interaction with State and local monitoring activities and the location of the crisis site emergency operations facilities must be considered. Conditions at the time will dictate FRMAC site selection.

\subsubsection{FRMAC Site Specifications}

A FRMAC should be located within 10 to 15 miles of the emergency scene to effectively carry out its mission. Because of the expected use of the DOE AMS assets, the FRMAC location should be convenient to an airport or a helicopter pad to facilitate rapid turnaround.

A FRMAC site for a large-scale deployment of 300 personnel or more requires an indoor workspace which is a minimum of 10,000 square feet with partitioned spaces for administrative functions and for specialized equipment, such as communications, photo, and still video. A large, fenced staging area is needed for shipping and storage of supplies, large trucks and analysis vans, and the setup of outdoor communications equipment. Adequate electrical service must be available.

The availability and suitability of the following facilities and resources must be considered in the selection of a FRMAC site:
A. Site access - airport and/or major highways to accommodate large trucks and vans
B. Communications - clear of interference, appropriate terrain for a satellite antenna; telephone trunk lines
C. Housing - hotels or military quarters 

D. Vehicle rental - several types of large trucks
E. Medical facilities - hospital or dispensary
F. Food services - round-the-clock catered service
G. Materials and services - office supplies, minor repairs, security

\subsubsection{Selection}

A FRMAC operating site will not be finally selected until an emergency occurs. This is due partly to the fact that the FRMAC may be responding in the aftermath of an earthquake, hurricane, or flood. A significant radiation release may preclude access to preselected FRMAC sites due to possible contamination. Therefore, any preselection of FRMAC sites is limited to simply identifying one or two potential locations for each major, fixed nuclear facility. The DOE Regional Radiological Coordinating offices should be informed of the identity and location of these potential FRMAC sites.

Members of the FRMAC advance party, in consultation with the State(s), LFA, and local authorities, will make the final selection of a FRMAC site based on the current emergency conditions.

\subsection{Information Flow and Priorities}

FRMAC's highest priority is to provide monitoring and assessment results to the State(s), LFA, and local authorities. In the event a release of radioactivity impacts a large area, the monitoring process will require many hours to acquire the data and additional time to assemble a full assessment of the extent and magnitude of that impact. Figure 4 indicates this information flow process from the bottom up. The goal is to replace the early model-based data used to project initial protective actions with actual environmental monitoring results.

The initial monitoring will likely focus on the protection of the public and the determination of the magnitude, direction, and extent of released radioactivity. Aerial surveys and ground monitoring will be utilized for this purpose. These first results are then used to direct a more detailed monitoring effort, with inhabited areas receiving first priority unless otherwise directed by the State(s). Finally, the monitoring will be continued until all of the surrounding contaminated area is characterized and impacts assessed.

Figure 4 details the FRMAC environmental data information flow, both internally and externally. Basically, the State(s) and LFA are users of the technical information gathered and assessed by the FRMAC. More than one state could be involved. Provisions will be made in the information flow to promptly report any monitoring results that represent an immediate threat to health effects.

Raw data coming into the FRMAC are quickly reviewed, stamped, and distributed to the State(s), LFA, and local representatives, and to all interested participants within the FRMAC. Processed, evaluated, and summarized data from the Evaluation and Assessment Division is approved for external distribution by the FRMAC Director. 


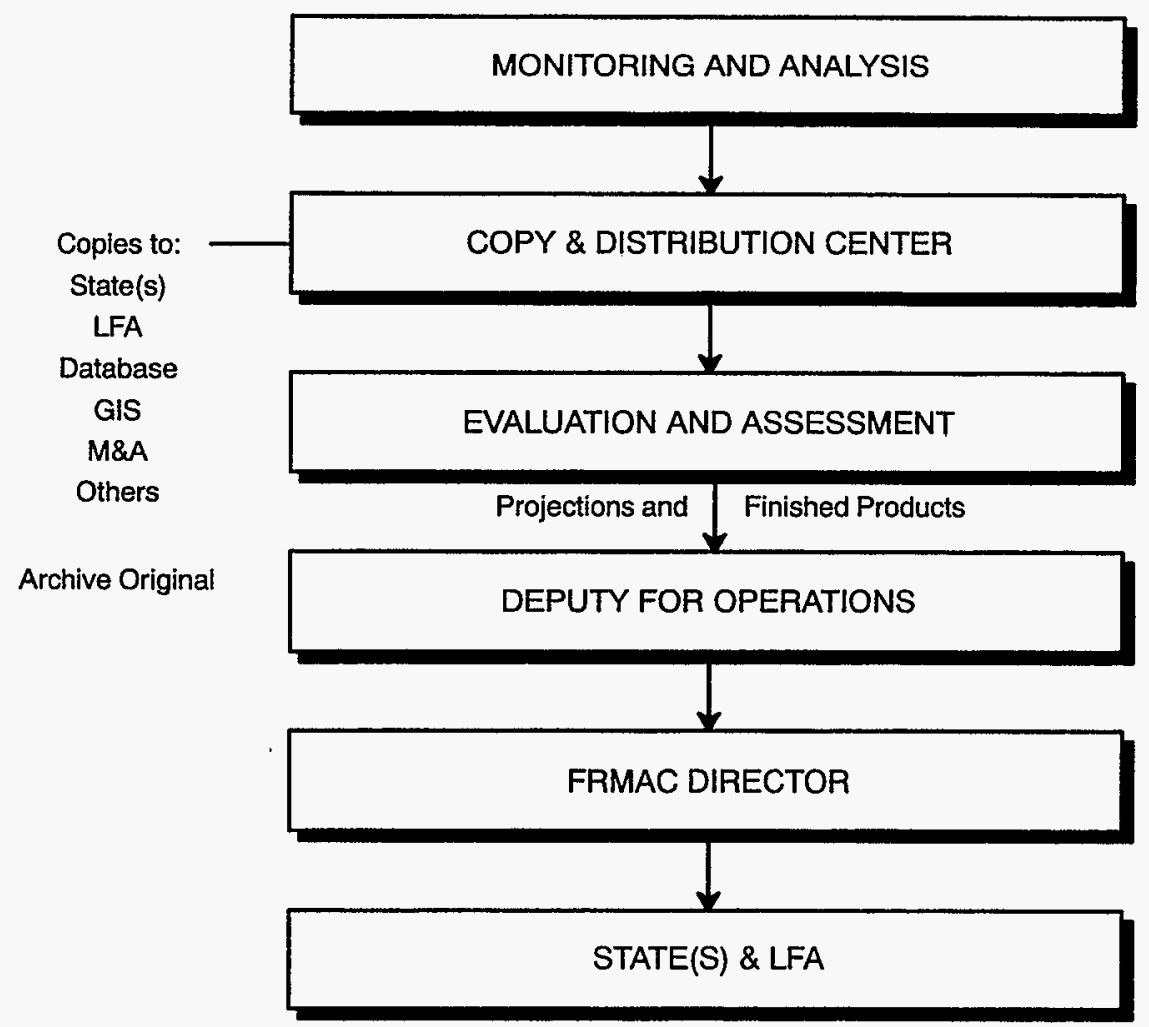

COLLECT AND PROCESS

INCOMING DATA

MAKE INTERNAL DISTRIBUTION OF ALL RAW DATA (10 MIN.)

CONDUCT SCIENTIFIC ASSESSMENTS AND DOSE PROJECTIONS

\section{DISTRIBUTE OUTPUT PRODUCTS TO STATE(S) AND LFA}

FIGURE 4. FRMAC ENVIRONMENTAL DATA INFORMATION FLOW

\subsection{FRMAC Data Output Products}

The general responsibility of the FRMAC is to effectively and efficiently manage the Federal resources in monitoring and assessing the environmental aspects of the off-site radiological situation. The results of this monitoring and assessment are provided to the State(s), LFA, and local authorities. The FRMAC will respond to specific requests made by the State(s), LFA, and local authorities as well as be prepared to produce some generic products.

Without a specific request for them, the State(s), LFA, and local authorities can expect that the FRMAC will work toward producing the generic products listed in the following sections. The majority of these products will be produced within the FRMAC by the Evaluation and Assessment Division, which will apply its resources to producing these products. Where possible, they will be presented along with some perspective on the radiological situation, as known at the time, in a form readily understandable to managers and decision makers.

\subsubsection{Plume Dispersion and Dose Projections}

The Lawerence Livermore National Laboratory (LLNL) Atmospheric Release Advisory Capability (ARAC) will provide plume and dose projections when provided with the current meteorological data 
and estimated source term. ARAC predictions will supplement those made by the facility operator and/ or the State(s) and LFA. Projections will be revised as verified field measurement data become available. The predicting group resides in the E\&A Division.

\subsubsection{Aerial Survey Data}

The DOE's Aerial Measuring System (AMS) will be available to conduct aerial radiological surveys at the emergency site. The AMS group resides in the M\&A Division. The order and priority of the AMS missions will depend upon whether the atmospheric release has terminated or is ongoing. If the release has terminated, the first mission would likely be performed in a serpentine pattern to cover the entire deposition area expeditiously. The results of this first mission are expected to identify the centerline location and direction, the extent of the measurable contamination in both width and length, the major isotopes contributing to the aerial results, and an estimate of the level of contamination (exposure rates or isotope concentrations).

Later missions will involve more detailed surveys. Each mission or flight is expected to take from two to three hours, with the results available one to three hours after a mission is completed. These results will be reviewed and issued to the State(s), LFA, and local authorities as soon as possible after the completion of each survey mission. AMS flights may involve the use of both helicopter and fixed-wing aircraft utilizing large sodium iodide gamma detectors. Sensitivities are such that small changes in background can be detected $( \pm 1 \mu \mathrm{R} / \mathrm{h})$.

\subsubsection{Reviewed Raw Data}

Ground-based radiation data (including exposure rates, sampling results, and isotopic concentrations of deposited activity) will be reviewed by the M\&A Division and provided to the State(s), LFA, and local authorities. Specific data points (required by the State[s], LFA, or other agencies) may be needed, particularly in the initial stages of an emergency when complete data are unavailable. These reviewed raw data will be screened for complete information such as times, locations, units, exponents, and instruments used. The review will also provide some assurance for consistency within the product since it is reviewed against current knowledge of the overall radiological situation. Reviewed raw data may also include data from samples of water, soil, vegetation, food products, and any other sample media. Evaluation consistent with potential health hazards may be included.

\subsubsection{Summarized Data}

Environmental radiation data from field teams and laboratories will be entered into a database for both short-term and long-term storage and retrieval. As required, the data can be condensed and summarized to show the radiation situation in specific areas or to correlate sample media from different types of surveys. For example, a summarized data sheet could be generated to show all of the external exposure rate or specific nuclide data taken in certain sectors, districts, or population areas over a given time period. 


\subsubsection{Exposure Rate and/or Contamination Contours}

FRMAC provides radiation contours in a color-coded format showing where the contamination is located and the associated radiation levels. Initially, projections of radiation patterns from radiological dispersion models are likely to be the only ones available. As environmental surveys are conducted, these contours will be refined or changed to be consistent with data from actual measurements. It is anticipated that contamination contours will be updated every few hours to represent the latest information received in the FRMAC. Where appropriate, the contours will be color-coded for ease of interpretation. The contour levels may be in exposure rates and isotope concentrations, depending on the type of emergency and needs of the State(s), LFA, and local authorities.

\subsubsection{Dose Projections from Actual Measurements}

Once enough data points are available, more realistic projections of doses to individuals and/or groups of individuals can be produced. The contour levels will include those applicable to the Protective Action Guides (PAGs) as well as any other levels of interest. For example, it may be appropriate to produce contours of the projected four-day, first-year, second-year, and fifty-year whole-body dose equivalent from external radiation for outdoor locations and/or for sheltered locations. A variety of assumptions or modifying factors may be included in these dose projections, including (but not limited to) weathering, resuspension, structure shielding, and occupancy rates. The FRMAC dose projections will be as realistic as possible using reasonable assumptions and transfer values consistent with the uncertainties involved. Such assumptions will be documented, or their sources referenced, and included with the assessments.

\subsubsection{FRMAC Data Center}

All of the environmental radiological data acquired by or furnished to the FRMAC will be stored in the FRMAC Data Center. The Data Center is designed to be: 1) comprehensive, 2) traceable, and 3) accountable. It will be comprehensive because it is intended to include every off-site environmental radiological data point. Every data point acquired by FRMAC will be traceable to an individual instrument, survey team, calibration, and procedure. The data center information is accountable because the FRMAC will stand behind the integrity of its results. The Data Center provides a means of accomplishing this by gathering environmental radiological information into a central location and compiling it in a common format with complete information on each measurement and/or sample.

The long-term design objectives of the Data Center are to: 1) build a comprehensive and traceable compilation of all environmental radiological data for long-term retention and use by EPA, the State(s), LFA, and local authorities, and 2) archive all of the information to allow reconstruction of knowledge of the radiological situation sometime in the future.

\subsubsection{Tailored Format for Users}

The FRMAC will present the off-site environmental radiological data to the State(s), LFA, and local authorities in a recognizable and useable format, and in a perspective understandable by managers 
and decision makers. Insofar as possible, there will be presentation-quality graphics summarizing data and impacts. Discrete data will be prepared in a clear, concise form, organized specifically for a particular purpose. Radiation levels in commonly used units and/or in values relative to recognizable Protective Action Guide (PAG) levels will be used. Where possible, plotted or contoured radiation levels will be in standard FRMAC color schemes. Information transmitted by fax, GIS, or still video will be produced in an easily readable and concise format with sufficient information to properly present the required data. Whenever possible, the provided information will be tailored to meet the intended users' purposes.

\subsubsection{Geographic Information System (GIS)}

The GIS is a computerized database management system which provides for the capture, storage, retrieval, analysis, and display of spatial (locationally defined) data. By having layers of information displayed on a computer screen and/or map, a person is allowed to "see" the relationship of one piece of information to another. The GIS is also a database in that attributes of a given piece of data can easily be referenced. For example, a specific school can be located on a map and applicable information about that school can be extracted by the database. The GIS can also calculate areas of interest. For example, a land use data layer can be overlaid onto a radiation plot to calculate the area of a given type of land use that lies within a given radiation zone.

Layers of information within the GIS may include: 1) geographic base data, 2) administrative data, 3) emergency response data, 4) land cover/land use, 5) critical industries, 6) radiation data, 7) dispersion model output, and 8) image data.

For example, emergency response data could include locations of evacuation routes, police and fire stations, hospitals and clinics, operation centers, shelters, and institutions (school, prisons, and nursing homes). Radiation data could include baseline background levels, TLD locations, continuous location of survey teams, AMS data, location of measurements and samples by type, exposure rate contours, integrated one-year dose projection contours, and isotopic concentration contours by dominant isotope.

\subsection{INTERFACING}

\subsection{DOE}

During the Emergency Phase, while the DOE is manager of the FRMAC, the FRMAC will keep DOE/ NV, the DOE/Region, and DOE/HQ informed of the utilization of the DOE assets, status of activities, and needs for additional resources, if applicable. Radiological data and results, if requested, will be transmitted to DOE/NV, the DOE/Region, and/or DOE/HQ, when approved for distribution by the LFA.

\subsection{State(s)}

During a major radiological emergency, the FRMAC will assist the State(s) in off-site environmental monitoring and assessment. To facilitate the requests from the State(s) to the FRMAC and the 
assessed data from the FRMAC to the State(s), liaison personnel will be exchanged. Also, State and local advisors are incorporated into the FRMAC Director's senior staff and M\&A, E\&A, and Support Divisions. Because of their local and professional knowledge, they provide valuable assistance in the efficient and optimal operation of the FRMAC in meeting the requirements of the State(s) and LFA.

\subsection{LFA}

The FRMAC Director will initiate discussions with the LFA staff as soon as technical assistance is requested. These discussions will address the conditions and status of the emergency and possible off-site consequences. Once the FRMAC is established, the LFA will provide appropriate emergency status updates to the FRMAC via the LFA liaison located at the FRMAC. This liaison will be the primary vehicle for transmitting the LFA off-site monitoring and assessment requirements to the FRMAC and the distribution of the FRMAC's assessed data to the LFA.

\subsection{EPA}

The EPA is notified if FRMAC has been requested for a radiological emergency. The EPA/ORIA provides a senior representative in the FRMAC to ensure that the data collected for the Data Center will provide the necessary information for long-term re-entry and recovery questions and as a basis for developing a long-term monitoring plan. As the emergency situation is brought under control, the EPA senior official prepares to assume management of the FRMAC from DOE.

\subsection{Other}

Other signatory agencies to the FRERP are provided space and support to integrate their monitoring and assessment activities into the FRMAC operations. Many of the agencies provide key specialists in technical areas of importance to the FRMAC monitoring and assessment mission. Included are specialists in food crops, milk production, water supplies, and critical industries. As full participants in the FRMAC, these agencies become part of the monitoring and assessment technical teams to assure that their areas of concern are addressed. These Federal agencies may include the EPA, NRC, DoD, USDA, HHS, and National Oceanic and Atmospheric Administration (NOAA). The responsible facility operator may also be represented at the FRMAC to provide updates on facility status.

\subsection{Community Interaction}

Due to the close working relations between the FRMAC elements and the surrounding communities, county and local government officials as well as emergency service liaison personnel will be invited to interact directly. with the FRMAC as required by the State(s). If requested, the FRMAC will provide liaison representatives to County and local EOCs. 


\section{APPENDIX A}

\section{ACRONYMS}

ALARA ......... As Low As Reasonably Achievable

AMS Aerial Measuring System

ARAC Atmospheric Release Advisory Capability

DFO Disaster Field Office

DoD Department of Defense

DOE Department of Energy

DOE/HQ ......... Department of Energy Headquarters

DOE HQ OEMT .... DOE Headquarters Operational Emergency Management Team DOE/NV .......... Department of Energy, Nevada Operations Office DOE/NV EOC ...... DOE/NV Emergency Operations Center E\&A ......... Evaluation and Assessment Division (FRMAC)

EG\&G/EM ....... EG\&G Energy Measurements EOC ........... Emergency Operations Center

EPA ........... Environmental Protection Agency

FCO ........... Federal Coordinating Officer

FDA .......... Food and Drug Administration

FEMA .......... Federal Emergency Management Agency

FRERP .......... Federal Radiological Emergency Response Plan

FRMAC ......... Federal Radiological Monitoring and Assessment Center

GIS ........... Geographic Information System

HHS .......... Department of Health and Human Services

HQ OPS CTR ....... NRC Headquarters Operations Center

JIC ............ Joint Information Center

LFA ........... Lead Federal Agency

LLNL ............ Lawrence Livermore National Laboratory

M\&A ........... Monitoring and Analysis Division (FRMAC)

NARP . . . . . . . . Nuclear Weapon Accident Response Procedures

NASA . . . . . . . . National Aeronautics and Space Administration

NDA ........... National Defense Area

NOAA ........... National Oceanic and Atmospheric Administration

NRC . Nuclear Regulatory Commission 
NSA .......... National Security Area

OEMT ........... Operational Emergency Management Team

PAG $\ldots . . \ldots \ldots$. Protective Action Guide

PAO .......... Public Affairs Officer (Federal)

PAR ............ Protective Action Recommendation

RAP .......... Radiological Assistance Program

REAC/TS . . . . . . . Radiation Emergency Assistance Center/Training Site

SFO ........... Senior FEMA Official

SSA $\ldots \ldots \ldots$. . Senior Scientific Advisor

USDA .......... United States Department of Agriculture 


\section{APPENDIX B \\ OTHER FRMAC DOCUMENTS}

FRMAC-11 ......... FRMAC Operations Plan, Emergency Phase (Working Draft)

FRMAC-12 . . . . . . . FRMAC Director's Handbook (Unpublished Draft)

FRMAC-20-92 ...... FRMAC Alert, Activation and EOC Operations

FRMAC-50 ......... FRMAC Evaluation and Assessment Technical Operations Plan (Working Draft)

FRMAC-51 ......... FRMAC Data Center Operations (Working Draft)

FRMAC-52 ......... FRMAC Evaluation and Assessment Handbook (Working Draft)

FRMAC-61 .......... FRMAC Monitoring and Analysis Manual (In Preparation)

FRMAC-70 ........ FRMAC Health and Safety Operations (In Preparation)

RAP/FRMAC Interface Plan (Draft) 


\section{APPENDIX C \\ KEY REFERENCE MATERIALS}

Assistant to the Secretary of Defense. Nuclear Weapon Accident Response Procedures (NARP) Manual, DoD 5100.52-M. Defense Nuclear Agency, Alexandria, Virginia, September 1990.

"Federal Radiological Emergency Response Plan (FRERP)." Federal Register, 50 Fed. Reg. 46542, November 8, 1985.

McKenna, T. et al. RTM-93 Response Technical Manual, NUREG/BR-0150, Vol. 1, Rev. 3. U.S. Nuclear Regulatory Commission, Division of Operational Assessment, Office for Analysis and Evaluation of Operational Data, March 1993.

DOE Order 5530.3. Radiological Assistance Program (1/14/92). Establishes DOE policy, procedures, authorities, and responsibilities for the RAP.

DOE Order 5530.4. Aerial Measuring System (9/20/91). Establishes DOE's Aerial Measuring System Program for the measurement of radionuclides over large areas.

DOE Order 5530.5. Federal Radiological Monitoring and Assessment Center (7/10/92), as revised.

44 CFR 351. Radiological Emergency Planning and Preparedness (10/1/92), p. 718-724. 


\section{DOE/HQ}

H.N. Amirmokri

S. Bartos

RADM C. J. Beers, Jr.

C. Coughlin

L. E. Gordon-Hagerty

V. J. McClelland

P. C. Stang

O.W. Taylor

W. J. Weaver

OSTI

(10)

(10)

\section{DOE/Region}

$\begin{array}{lll}\text { J. E. Straka } & \text { AL } & (10) \\ \text { M.D. Holland } & \text { BAO } & (10) \\ \text { E. J. Jascewski } & \text { CH } & (10) \\ \text { C. Ogilvie } & \text { ID } & (10) \\ \text { B. Davis } & \text { OR } & (10) \\ \text { K. A. Beecher } & \text { RL } & (10) \\ \text { A. L. Remick } & \text { OAK } & (10) \\ \text { S. L. Southern } & \text { SRO } & (10)\end{array}$

\section{DOE/NV}

G.C. Allen

N.C. Aquilina

H.U. Brown

M.W. Chilton

B.W. Church

R. C. Dey

J.K. Magruder

M. A. Marelli

C. E. McWilliam

P. G. Mueller

R.M. Neison

V. E. Niemann

S. C. Ronshaugen

C.A. Santilli

G.B. Snodgrass

C. L. West

T.D. Wiard (WAMO)
$\mathrm{NRC} / \mathrm{HQ}$

(5)

(5)

T. J. McKenna

R. L. Spessard

E. D. Weinstein

(2)

(25)

DNA/HQ

LTC D.T. Tompkins

(10)

EPA/HQ/ORIA

A. E. Newman

M. T. Oge

EPA/ORIA/NAREL/AL

E. L. Sensintaffer

J.M. Smith

S. T. Windham

EPA/ORIA LVF

G.D. Dempsey

EPA/EMSL

P. J. Weeden

(10)

FEMA/HO

V. E. Adler

(2)

T. M. Antush

(50)

L. Buchbinder

R. P. Fletcher, Jr.

V. L. Wingart
FEMA EMI

R. J. Gantt

NASA

J. R. Reynolds

LANL

T. C. Hower

K. L. Groves
(2)
NOAA/HQ

B. Hicks

(20)

HHS

E. K. Gray

J. A. Rabb

(10)

USDA

G. E. Bickerton

LLNL

P. E. Barry

T. J. Sullivan

PAI

D. L. Duncan

R. C. Morse

REECo

K. B. McGlothlin

ARL/SORD

D. Randerson

EG\&G/EM

Z. G. Burson LVAO

H.W. Clark LVAO

J. F. Doyle LVAO

C.K. Mitchell LVAO

S.R. Rohrer LVAO

G.R. Shipman WAMO

W.J. Tipton LVAO

P. H. Zavattaro LVAO

\section{LIBRARIES}

RSL

TIC

WAMO
FEDERAL RADIOLOGICAL MONITORING

ASSESSMENT CENTER (FRMAC)

OVERVIEW OF FRMAC OPERATIONS

DOE/NV-358

FRMAC-10-94

REVISION 2

JULY 1994 